\title{
Antioxidant and Antibacterial Study of 10 Flavonoids Revealed Rutin as a Potential Anti-Biofilm Agent in Klebsiella Pneumoniae Strains Isolated From Hospitalized Patients
}

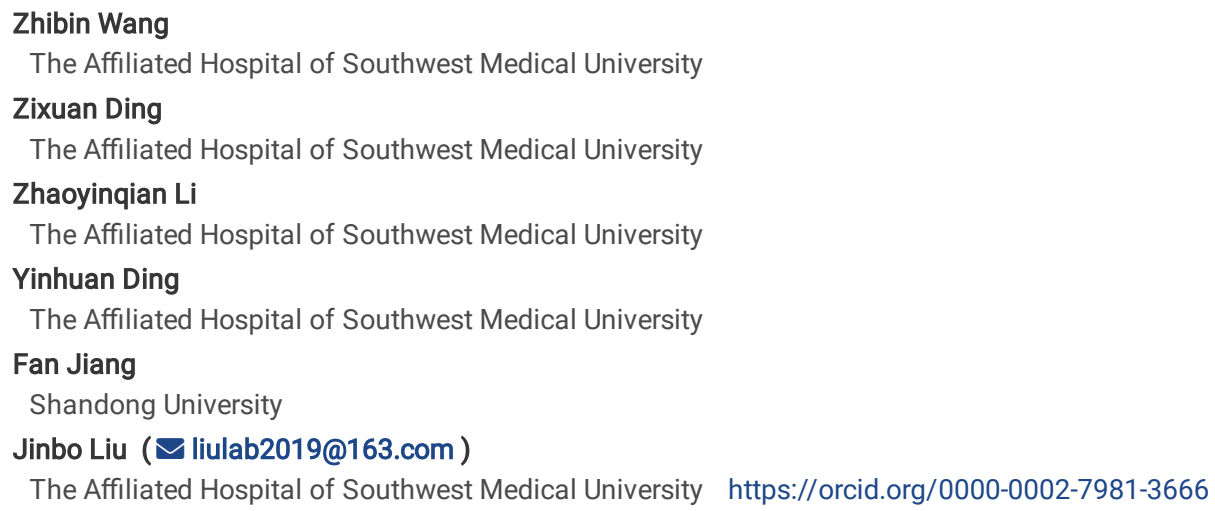




\section{Abstract}

Background: The emergence of multidrug resistance (MDR) and extensively drug-resistance (XDR) of Klebsiella pneumoniae strain has brought great threaten to traditional antibiotics. Previous studies showed that plant-derived flavonoids have inhibitory functions on pathogens. However, In $K$. pneumoniae, the antibacterial activities of different flavonoids on the growth and biofilm formation remains a mystery. The aim of the present study is to evaluate the antioxidant abilities of different flavonoids and to identify their inhibitory effects on K. pneumoniae growth and biofilm formation.

Results: Totally 10 flavonoids representing 4 major categories were screened and used in this study. The antioxidant capacity of each flavonoid was evaluated through a DPPH assay. Rutin showed highest free radical scavenging capacity, followed by kaempferol, luteolin, quercetin, apigenin, hesperidin, sinensetin, naringenin, naringin and 3,5,6,7,8,3',4'-heptamethoxyflavone. The inhibitory effect of rutin and naringin on bacteria growth were compared. The antibacterial activity of flavonoid is highly correlated with the antioxidant capacity. Among these flavonoids, rutin showed the best inhibitory capacity against both the

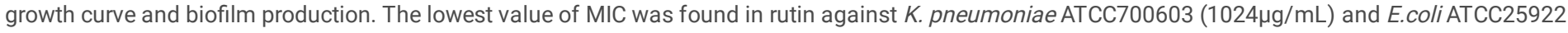
$(512 \mu \mathrm{g} / \mathrm{mL})$. The MBIC were not found. The expression profiles of 15 genes were analyzed in biofilm cells both with and without rutin treatment. The correlation analysis showed the $m r k A$ gene expression was positively correlated with the biofilm biomass accumulation.

Conclusions: Our study indicated that flavonols showed stronger antibacterial activities. The biofilm production is correlated with several gene expression rather than one. Rutin is a potential agent to inhibit the $K$. pneumoniae biofilm formation.

\section{Background}

Klebsiella pneumoniae (K. pneumoniae), an ubiquitous gram-negative encapsulated bacterium, has been reported and recognized as a strong risk to public health due to its high frequency of drug-resistance[1]. This opportunistic pathogen is widespread in the mucosal surfaces of different environments, such as soil, water, plants, animals and humans, causing a wide range of infections including pneumonia, urinary tract infection and liver abscesses among people with low immunity, even healthy ones[2]. K. pneumoniae is always considered as a most important pathogen bacteria as it poses not only community infections but also nosocomial infections[3]. In recent years, it was newly reported that drug-resistant $K$. pneumoniae can acquire virulence gene and as well, virulent $K$. pneumoniae can also obtain drug-resistance genes, thus making this strain resistant to the antibiotic class of 'last resort'[4]. In addition, the biofilm forming ability of $K$. pneumoniae are further contribute to their drug resistance, resulting in higher mortality[5]. Thus, it is urgent to develop new strategies or novel antibacterial agents to fight this pathogen.

Development of new antimicrobial agents to K. pneumoniae is particularly challenging due to its complicated mechanisms of drug resistance[6]. Among these mechanisms, biofilm forming is a highly correlated one[7]. Biofilms are such complex assemblage of microbial cells covered with self-produced matrix[8]. Many K. pneumoniae are able to form biofilms[9], where bacteria are surrounded by extracellular polymeric substances (EPS) such as polysaccharides, nucleic acids and proteins[10]. Compared with none biofilm producer, pathogens inside the biofilms are notoriously known for higher resistance to both inflammatory defense system of the host and antibiotics, which can lead to persistent infections or even, treatment failure[11].

Associated with high cost and low efficiency, the pace of new antibiotics emergence is increasingly limited[12, 13]. However, plant-derived flavonoids have been increasingly attracting researcher's attention due to their potential to be substitutes for antibiotics[14]. Composed of more than 8000 known compounds, plant-derived flavonoids are rich resource for new antibacterials discovery[15]. Flavonoids are naturally-occurring polyphenols and have been reported to contain a wide range of significant pharmacological functions including anticancer[16], anti-inflammation[17] and antiviral[18]. In addition, flavonoids are also well known as antibacterial agents against a wide range of pathogenic microorganisms[14], such as Staphylococcus aureus[19], Vibrio harveyi[20], Pseudomonas aeruginosa[21] and Enterococcus faecalis[22]. Several flavonoids, namely, fisetin, phloretin and curcumin, showed inhibitory effect on biofilm of multidrug-resistant Acinetobacter baumannii isolates[23]. However, in K. pneumoniae strains, the antioxidant and antibacterial effects of most flavonoids are still unclear.

In the past few years, we have studied citrus flavonoids and find over 80 citrus components in citrus plants (unpublished data). These compounds can be classified into four major types, namely flavones, flavonols, flavanones, and flavanonols according to their basic structures[24]. In present study, 10 flavonoids representing 4 major classes were studied. The capacity of antioxidant were evaluated through DPPH assay. The functions of different flavonoids on strain growth and biofilm formation were identified and compared. The MIC and MBIC were screened. The relationship between the gene expression and the biofilm formation was discussed. The aim of this study is to screen active flavonoid and to reveal the inhibitory mechanism of active flavonoid in $K$. pneumoniae.

\section{Materials And Methods}

\section{Clinical isolates and growth conditions}

A total of 177 no duplicate K. pneumoniae isolates were collected from blood samples in the Affiliated Hospital of Southwest Medical University (Luzhou, China ) over the period from July 2018 to June 2020. All strains were cultured in Luria-Bertani broth (LB, Haibo, Qingdao, China) media at $37^{\circ} \mathrm{C}$ with shaking or as static cultures, as required.

\section{Chemicals}

Flavonoids including naringenin, naringin, hesperidin, kaempferol, quercetin, rutin, apigenin, luteolin, sinensetin and 3,5,6,7,8,3',4'-heptamethoxyflavone were purchased from Aladdin Chemistry Co., Ltd. (Shanghai, China). The chemical 2,2-diphenyl-1-picrylhydrazyl (DPPH) was obtained from Sigma Aldrich Co. (Shanghai, China). The flavonoid stocks were prepared in dimethyl sulfoxide (DMSO). All chemicals used in this study were of analytical grade. 
As a stable free radical $\searrow$ the DPPH was used to evaluate the efficiency of antioxidant and antiradical of 10 flavonoids. The method was adapted to previous study $[25,26]$ and slightly modified. The DPPH assay was conducted as follows. Fabrication of standard curve-The $2.5 \mathrm{mg}$ DPPH powder was weighted and dissolved in methanol, the standard stock solution of $2.5 \times 10^{-2} \mathrm{mg} / \mathrm{mL}$ was prepared. Then a series of solutions of $0,5,10,15,20 \mathrm{and} 25 \mu \mathrm{g} / \mathrm{mL}$ were separately made. The absorbance of each solution at $515 \mathrm{~nm}$ was measured with a Beckman Model DU650 spectrophotometer. The standard curve was drawn according to the absorbance value. DPPH residual rate detection- The $12,6,3$ and $1.5 \mathrm{mg} / \mathrm{mL}$ solutions were prepared separately of 10 flavonoids. Ascorbic acid was used as control. Reaction tubes of $10 \mathrm{~mL}$ were prepared and each was added in $100 \mu \mathrm{L}$ flavonoids solution and $3.9 \mathrm{~mL}$ DPPH solution $\left(2.5 \times 10^{-2} \mathrm{mg} / \mathrm{mL}\right)$. Methanol was used as empty control. The absorbance was measured at different time points. The DPPH residual rate was calculated out according to the standard curve.

\section{Determination of minimum inhibitory concentration}

The K. pneumoniae ATCC700603 and E.coli ATCC25922 strain were cultured in LB agar medium for $24 \mathrm{~h}$ at $37^{\circ} \mathrm{C}$. The antibacterial ability of 10 flavonoids were determined by minimum inhibitory concentration (MIC). The MIC was evaluated through micro-broth dilution method performed in 96-well micro-plates according to the methods previously reported[27]. Briefly, K. pneumoniae ATCC700603 and E.coli ATCC25922 were cultured in LB solid medium and grown overnight at $37^{\circ} \mathrm{C}$ without shaking. Then, $100 \mu \mathrm{L}$ bacterial suspension $\left(10^{\wedge} 6 \mathrm{cfu} / \mathrm{mL}\right)$ was transferred to each well. Then, $100 \mu \mathrm{L}$ of each dissolved flavonoid stock was twofold serially diluted (ranging from $1 \mu \mathrm{g} / \mathrm{mL}$ to $1024 \mu \mathrm{g} / \mathrm{mL}$ ) and added to each well, making the final volume of $200 \mu \mathrm{L}$ in each well. The empty control was performed by 3 wells filled with LB only and the positive control was conducted in 3 wells filled with LB and bacteria. Ciprofloxacin was used as positive drug control. The 96 -well plates were covered and incubated for $16 \mathrm{~h}$ at $37^{\circ} \mathrm{C}$ with shaking ( $\left.150 \mathrm{rpm}\right)$. The MIC was determined when no visible bacterial growth can be seen (absence of turbidity) in the well.

\section{Bacterial strains and growth conditions}

Bacterial species were identified by standard methods with a MicroScan WalkAway 96 Plus System (Siemens, Germany). K. pneumoniae ATCC700603 and E.coli ATCC25922 were purchased from China National Health Inspection Center.

All procedures performed were approved by the Ethical Committee of the Affiliated Hospital of Southwest Medical University and were in accordance with the tenets of the 1964 Helsinki declaration and its later amendments. All strains were cultured in LB medium at $37^{\circ} \mathrm{C}$. Before testing, the microorganisms were transferred on Mueller-Hinton agar (MHA, Liofilchem, Italy) and cultured over night at $37^{\circ} \mathrm{C}$. Subsequently, $10 \mathrm{~mL}$ of Mueller Hinton broth (MHB, Scharlau, Spain) were inoculated with one representative colony of each organism taken from MHA, then cultured overnight $\left(37^{\circ} \mathrm{C}, 150 \mathrm{rpm}\right)$ and used as source of inoculum for each assay.

\section{Growth curve measurement}

Stationary K. pneumoniae cultures were diluted $1: 1000$ in LB and incubated at $37^{\circ} \mathrm{C}$ with shaking $(220 \mathrm{rpm})$. Each well of a 96 -well polystyrene microtiter culture plate (Costar \#3524, Corning, NY, USA) were filled with $10 \mu \mathrm{L}$ of the overnight culture diluted to a final concentration of $1.5 \times 10^{\wedge 8} \mathrm{cfu} / \mathrm{ml}$ and $190 \mu \mathrm{L}$ of LB broth mixed with rutin to a final concentration of $512 \mu \mathrm{g} / \mathrm{mL}$. Sterile LB was added to the last three wells and used as a negative control. The $96-\mathrm{well}$ plates were covered and incubated for $24 \mathrm{~h}$ at $37^{\circ} \mathrm{C}$ with shaking (150 rpm). The growth was measured every $2 \mathrm{~h}$ at OD 590 using an microplate reader. All experiments were performed in triplicate.

\section{Biofilm formation assay}

Crystal violet (CV) staining was used in this study to quantify the biofilm formation. The assay was performed as previously described[28, 29]. The procedures was slightly modified. Briefly, for each strain, three wells of the $96-$ well plate were filled with $180 \mu \mathrm{L}$ LB broth and $20 \mu \mathrm{L}$ of the overnight culture. The overnight culture was grown at $37^{\circ} \mathrm{C}$ and diluted to a final optical density of 0.1 at $600 \mathrm{~nm}$ before use. Wells filled with nothing and sterile LB broth were used as empty control and negative control, respectively. After incubation for $24 \mathrm{~h}$ at $37^{\circ} \mathrm{C}$, each well was washed three times with phosphate-buffered saline (PBS). The 96 well plate need to be dried at $60^{\circ} \mathrm{C}$ for 30 minutes and stained for 15 minutes with $200 \mu \mathrm{L} 0.1 \%(\mathrm{w} / \mathrm{v}) \mathrm{CV}$ for 30 min at room temperature. After that, each well was washed three times with distilled water and air-dried. The dye bound of the adherent cells was dissolved in $200 \mu \mathrm{L}$ of $95 \%$ ethanol (Merck, Germany). The $590 \mathrm{~nm}$ absorbance was quantified using a microplate reader. All assays were performed in triplicate.

Biofilm-forming capacities of the isolates were evaluated by the value of cut-off OD, termed as ODC. The OD was defined as three standard deviations above the mean $O D$ of the negative control, and the following categories were established: $O D \leq O D C$, non-biofilm producers $(-)$; ODC $<$ OD $\leq 2 \times O D C$, weak biofilm producers $(+) ; 2 \times O D C<O D \leq 4 \times O D C$, moderate biofilm producers $(++)$ and $O D>4 \times O D C$, strong biofilm producers $(+++)[23]$.

\section{Quantitative reverse transcription (qRT)-PCR}

The expression levels of 15 genes were determined from biofilm-grown cells using qRT-PCR. Briefly, bacteria were grown in LB broth at $37{ }^{\circ} \mathrm{C}$ in a 6 -well microtiter plates(LG18-301C-1H, Lige Science, Guangzhou, China) and, after incubation for 24 hours, each well was gently washed and biofilm cells were removed from the well surface using a cell scraper and resuspended in saline solution. Total RNA was extracted using an RNeasy Mini Kit (Qiagen) and cDNA was synthesised using the RevertAid First Strand cDNA Synthesis Kit (Thermo Scientific) according to the manufacturers' instructions. The qRT-PCR was performed with an Applied Biosystems 7500 RT-PCR system using a SYBR Green RT-PCR Kit (Qiagen) and the primer pairs listed in Table 1. 
In K. pneumoniae, biofilms formation are mediated by a wide rage of biological processes and genetic factors, including type I fimbriae biosynthesis(fim $H$ )[30], type III fimbriae biosynthesis( $m r k A$ and $m r k D$ ), virulence genes(entB and fimH-1)[31], lipopolysaccharide (LPS) biosynthesis( $w z m$ and $w b b M)$ [32], poly- $\beta-1,6-\mathrm{N}$ acetyl-d-glucosamine polysaccharide secretion(pgaA)[5], quorum-sensing(QS)(IuxS)[33], capsular polysaccharide(CPS)(treC, wabG, $r m p A$ and $m a g A)[5]$, colonic acid (wcaJ)[34], allantoin (allS)[35], capsule-associated virulence

gene $(w c a G)[36]$ and siderophore-associated gene(entB)[31]. Most of these genes are virulence gene.

Primers were synthesized by Shanghai Biotech (Shanghai, China). The relative expression levels of tested genes were normalised to the expression of the 16sRNA gene. Each sample was run in triplicate and the means of $\mathrm{Ct}$ values were obtained for analysis. The relative gene expression was represented as fold change between the (-rutin) and (+rutin) treatment. Data were analysed using the $2^{-\Delta \Delta C t}$ method.

\section{Statistical analysis}

The Student's t-test was used to analyse the difference in biofilm formation ability and gene expression levels. Statistical analysis was performed with GraphPad Prism 7.01 software and IBM SPSS Statistics 23 software.

\section{Correlation analysis}

The correlation analysis was conducted through Pearson's correlation analysis. Three separated biological replicates of each assay were used for analysis.

\section{Results}

\section{Antioxidant capacity of flavonoids}

To identify the correlation between the antioxidant capacity and the related molecular structures of active flavonoids, and to develop new drugs that are less likely to induce resistance to treat drug-resistant bacteria, 10 components representing 4 major flavonoids categories were screened and evaluated through DPPH assay in present study (Table 2). The results showed that among the 4 major classes of flavonids, flavonols showed the highest free radical scavenging capacity, followed by flavones and flavanones. The polymethoxylatedflavones were supposed to have the lowest antioxidant activity (Figure 1). Furthermore, within the flavonols, rutin exhibited highest free radical scavenging ability, followed by kaempferol and quercetin, respectively.

\section{Clinical characteristics and biofilm formation abilities of $K$. pneumoniae strains}

The biofilm formation abilities of 177 clinical isolates of $K$. pneumoniae were evaluated by crystal violet staining. The results were shown in Table 3 . Among the 177 isolates, the positive rate of biofilm producer was $88.14 \%(156 / 177)$, of which strong (+++), moderate (++), and weak (+) biofilm producing strains account for $10.73 \%$ (19/177), 16.95\% (30/177) and $60.45 \%$ (107/177), respectively. The rate of strong biofilm producer was low among these clinically isolated $K$. pneumoniae strains, though the positive rate of biofilm producer was high.

\section{Minimum inhibitory concentration of 10 flavonoids}

The minimum inhibitory concentration, termed as MIC of flavonoids against K. pneumoniae ATCC700603 and E.coli ATCC25922 were evaluated. Flavonols showed higher level of inhibitory effect than other categories of flavonoids, maybe due to their strong antioxidant capacity. However, most of the flavonoids are not strong inhibitory agents against neither K. pneumoniae, nor E.coli, as the lowest MIC was $512 \mu \mathrm{g} / \mathrm{mL}$ of rutin against E.coli ATCC25922 and 1024 $\mu \mathrm{g} / \mathrm{mL}$ of rutin against K. pneumoniae ATCC700603. Other flavonids were found no obvious inhibitory effects even when the concentration of these flavonoids increased to $1024 \mu \mathrm{g} / \mathrm{mL}$ (Table 4).

\section{Inhibitory effect of rutin on $K$. pneumoniae growth}

From the results above, we found rutin was the most potential antimicrobial agent. In order to confirm the inhibitory effect of rutin against $K$. pneumoniae strains, the growth of two drug-resistant K. pneumoniae isolates (Kpn495 and Kpn499) were evaluated by morphological observation and growth curve changes. Furthermore, naringin and the combination of rutin and naringin were also used to evaluate their inhibitory effect against $K$. pneumoniae (Figure 2). The concentration of both rutin and naringin used in this session was increased to $50 \mathrm{mg} / \mathrm{mL}$ as no obvious inhibitory effect was found at low concentration.

In solid media, both rutin and naringin showed inhibitory effect on $K$. pneumoniae growth. Rutin showed better inhibitory effect than naringin both in Kpn495 and Kpn499 strains. In addition, rutin showed significant inhibitory effect on the 24-h growth curve of both Kpn495 and Kpn499(Figure $2 \mathrm{c}$ and d).

The combination of these two components were found no significant inhibitory effects. In contrast, the combination of rutin and naringin even promoted the growth of Kpn495 strain.

\section{Inhibitory effect of rutin on biofilm formation}

The minimum biofilm inhibitory (MBIC) effect of flavonoids against biofilm formation were measured in 96-well polystyrene plates using a crystal violet assay. The tested flavonoids exhibited varying levels of anti-biofilm activity against $K$. pneumoniae strains though the MBIC was not observed in this study (Figure 3 ). Of the 10 flavonoids, rutin, kaempferol and quercetin at $256 \mu \mathrm{g} / \mathrm{ml}$ exhibited biofilm inhibition, whereas naringin, sinensetin and 3,5,6,7,8,3',4'heptamethoxyflavone increased biofilm formation in Kpn140. When the concentration of rutin increased to $512 \mu \mathrm{g} / \mathrm{ml}$, more flavonoids, like naringin, kaempferol, quercetin, rutin, luteolin, sinensetin and 3,5,6,7,8,3',4'-heptamethoxyflavone showed inhibitory effect, but only kaempferol and rutin showed significant variations (Figure 3a). Regarding to Kpn 173, four flavonoids, that is kaempferol, quercetin, rutin and luteolin showed inhibitory effect on biofilm 
formation when the concentration was at $256 \mu \mathrm{g} / \mathrm{ml}$, others had little effect (Figure 3b). When the concentration increased to $512 \mu \mathrm{g} / \mathrm{ml}$, another three flavonoids, that is, naringin, sinensetin and 3,5,6,7,8,3',4'-heptamethoxyflavone reduced biofilm formation. Among these 10 flavonoids, only kaempferol, quercetin, rutin and luteolin showed dose-dependent inhibitory effect and only rutin showed significant inhibition. The strongest inhibitors against biofilm formation were rutin, kaempferol and quercetin, they are all flavonols.

To identify the correlation between the concentration of rutin and its anti-biofilm capacity, five different concentrations were used to treat the biofilm and the inhibitory effects were compared (Figure $3 \mathrm{c}$ and d). Rutin significantly decreased the biofilm production when the concentration was at $512 \mu \mathrm{g} / \mathrm{mL}$ and 256 $\mu \mathrm{g} / \mathrm{mL}$. However, when the concentration lowered to $128 \mu \mathrm{g} / \mathrm{mL}$, the inhibitory effect was not significant. When the concentration decreased to $64 \mu \mathrm{g} / \mathrm{mL}$ or 32 $\mu \mathrm{g} / \mathrm{mL}$, no inhibition was found.

\section{Gene expression analysis}

To identify key factors that involved in biofilm formation process, totally 15 genes related to type I and III fimbriae biosynthesis, virulence factors, lipopolysaccharide (LPS) biosynthesis, poly- $\beta-1,6-\mathrm{N}$-acetyl-d-glucosamine polysaccharide secretion, quorum-sensing(QS), capsular polysaccharide(CPS), colonic acid (wcaJ), allantoin, capsule-associated virulence gene and siderophore-associated gene were analyzed in biofilm cells before and after the rutin treatment, respectively. In Kpn140, 7 genes ( $m r k A, w z m, w b b M$, luxS, tre $C$, wabG, entB) were detected to show significant expression differences with and without rutin treatment. Among these genes, wzm, wbbM and ent $B$ were up-regulated while, $m r k A$, luxS, tre $C$ and wabG were down-regulated after rutin treatment in biofilm cells. The expression level of luxS, wabG

and $m r k A$ gene were down regulated 69 -fold, 61 -fold and 8.8-fold after rutin treatment, respectively. However, the up-regulated genes were found to have very low expression level though the changes were significant after rutin treatment(Figure 4a).

In Kpn173, 8 of the 15 genes were found to significantly changed their transcription levels after rutin treatment. Among the 8 genes, 3 ( $w z m, w b b M$ and entB) were up-regulated and the others were down-regulated (Figure 4b). The wabG and luxS gene decreased their expressions by approximately 34 - and 7-fold, respectively.

Among the 15 genes analyzed in this study, most of them showed low level of expression alterations after rutin treatment. However, the luxS gene and wabG gene showed high level of expression in the biofilm cells and decreased their expression level sharply after rutin treatment in both Kpn140 and Kpn173.

\section{Correlation between biofilm and gene expression}

To identify the function of these genes in biofilm cells, in particular their response to rutin treatment and biofilm formation, the correlation between gene expression and biofilm biomass was studied (table 5). Of these genes, 7 of them were highly correlated with biofilm biomass. The expression of $m r k A$ gene was positively correlated with the biofilm production $(\mathrm{R}=0.694)$. However, the results showed the genes, $w z m, w b b M, m a g A, w c a J, a l l S$ and $e n t B$ were negatively correlated with biofilm biomass, as their coefficients were $-0.846,-0.815,-0.903,-0.823,-0.669$ and -0.737 , respectively. Though the luxS gene showed highest level of expression, the correlation between its gene expression and the biofilm biomass was not significant. Furthermore, co-expression of genes were found in this study.

\section{Discussion}

As an opportunistic Gram-negative pathogen, K. pneumoniae can cause a wide range of severe infections like pneumonia, sepsis and urinary tract infections[37]. Furthermore, this strain is associated with invasive disease in community, while in hospital, it has a marked propensity to acquire drug resistance[38]. From previous studies we observed, associated with multi-drug resistance, K. pneumoniae is resistant to all, or almost all, available antibiotics[39]. As a result, it is urgent to develop new antibacterial agents or novel strategies to fight the strain.

Plant-derived flavonoids have potential properties in the discovery of new antibacterial agents[40]. In some cases, it was showed that flavonoids exhibited up to 6-fold stronger antibacterial activities than standard drugs in the market[41]. However, in this study, we evaluated 10 flavonoids and found the MICs of most tested flavonoids were higher than $1024 \mu \mathrm{g} / \mathrm{mL}$, indicating that the antibacterial ability of flavonoids was not strong especially when the flavonoids were in low concentration. The lowest MIC values were observed in rutin of $1024 \mu \mathrm{g} / \mathrm{mL}$ and $512 \mu \mathrm{g} / \mathrm{mL}$ against K. pneumoniae ATCC700603 and E.coli ATCC25922, respectively. This result showed the inhibitory effect varied among different bacteria species. Regarding to biofilm, no MBIC was observed but the inhibitory effect of rutin against the biofilm formation was proved when the concentration of rutin was at $256 \mu \mathrm{g} / \mathrm{mL}$ or higher than that.

Flavonoids are secondary metabolites with C6-C3-C6 skeleton and widely distributed in plant kingdom[42], including more than 8,000 compounds[43]. As a result, it is not possible to evaluate them one by one. For our first step, in present study, 10 flavonoids representing 4 major flavonoid categories were screened and studied.

Previous study showed free hydroxyl can donate hydrogen and electron and hence responsible for the radical scavenging ability[44]. In this study, we found the free radical scavenging ability was also correlated with the number of hydroxyl. Flavonols contain more (at least 4 hydroxyl) hydroxyl and they showed stronger free radical scavenging ability than others. In addition, luteolin showed higher free radical scavenging ability in comparison with apigenin, may be due to its 4 hydroxyl, though both of them are in flavones group.

Flavonoids were found to perform antibacterial actions through a series of mechanisms, such as bacterial toxin production, inhibition of nucleic acid synthesis and biofilm formation[45]. Biofilm formation ability is increasingly considered when develop new antibacterial drugs as bacteria inside biofilms can increase 10-1000 fold resistance[46]. Compared with conventional antibiotics, flavonoids are rich in nature and not easily to generate drug-resistance. 
However, the inhibitory effects of flavonoids on $K$. pneumoniae are still unclear. In this study, 15 genes related to biofilm formation, involving in various biological processes were studied with and without rutin treatment. The $m r k A$ gene was revealed to tightly correlated with the biofilm formation. This result indicated that the $m r k A$ gene may play vital role in biofilm formation.

The luxS gene is a key factor involved in quorum sensing (QS) system in bacteria[47]. QS is a universal mechanism of cell density and interspecies communication through which the bacteria can regulate various gene and biological process, including biofilm formation[48]. In both Kpn140 and Kpn173, the IUXS gene's expression was high in biofilm cells without rutin. However, luxSgene's expression decreased sharply when the biofilm was inhibited by rutin. Furthermore, we can conclude the importance of IuxS, as several biofilm related genes were found to be co-expressed with luxS, though the correlation between luxS gene expression and biofilm formation was not significant. These results shed light on the inhibitory mechanism of rutin on the biofilm formation in K. pneumoniae strains, which could aid in developing new strategies for infection control.

\section{Conclusion}

Among these flavonoids, rutin showed stronger free radical scavenging capacity and antibacterial activity. Of the biofilm related genes, the expression of /uxS gene was significantly induced by rutin treatment in biofilm cells. The biofilm biomass was positively correlated with the expression of a type III fimbriae biosynthesis gene, $m r k A$. Rutin could be a potential agent to inhibit the $K$. pneumoniae biofilm formation.

\section{Abbreviations}

MDR: multidrug resistance; XDR: extensively drug-resistance; DPPH: 2,2-diphenyl-1-picrylhydrazyl; MIC: minimum inhibitory concentration; MBIC: minimum biofilm inhibitory concentration; EPS: extracellular polymeric substances; LB: Luria-Bertani broth; DMSO: dimethyl sulfoxide; MHA: Mueller-Hinton agar; MHB:Mueller-Hinton broth.

\section{Declarations}

\section{Acknowledgement}

We are grateful to Professor Xiaochun Zhao for help with the guidance of academic thoughts.

\section{Funding}

Zhibin Wang received the launching scientific research funds for doctors (19076) and funding for the start of post-doctoral research (20003) from the Affiliated Hospital of Southwest Medical University, Luzhou 646000 , China. This study was also founded by Luzhou City-Southwest Medical University joint program (2020LZXNYDJ46).

\section{Authors' contributions}

Z-BW, F-J and J-BL designed the experiments; Z-BW and Z-XD conducted the experiment; Z-BW and Z-YQL isolated the strains; Z-BW and Y-HD identified the strains; Z-BW and J-BL analysed the data; Z-BW, F-J and J-BL prepared manuscript; F-J and J-BL supervised the research and revised the manuscript. All authors have read and approved the manuscript for publication.

\section{Ethics approval and consent to participate}

Not applicable.

\section{Consent for publication}

Not applicable.

\section{Competing interests}

The authors declare that they have no competing interests.

\section{Availability of data and materials}

The data set supporting the conclusions in this article is available from the corresponding author on reasonable request.

\section{References}

1. Ernst CM, Braxton JR. Adaptive evolution of virulence and persistence in carbapenem-resistant Klebsiella pneumoniae. Nature medicine. 2020;26(5):70511.

2. Magill S, Edwards J, Bamberg W, Beldavs Z, Dumyati G, Kainer M, Lynfield R, Maloney M, McAllister-Hollod L, Nadle J, et al. Multistate point-prevalence survey of health care-associated infections. N Engl J Med. 2014;370(13):1198-208.

3. Becker L, Kaase M, Pfeifer Y, Fuchs S, Reuss A, von Laer A, Sin M, Korte-Berwanger M, Gatermann S, Werner G. Klebsiella pneumoniaeGenome-based analysis of Carbapenemase-producing isolates from German hospital patients, 2008-2014. Antimicrobial resistance and infection control $2018,7: 62$. 
4. Ramirez MS, Iriarte A, Reyes-Lamothe R, Sherratt DJ, Tolmasky ME. Small Klebsiella pneumoniae Plasmids: Neglected Contributors to Antibiotic Resistance. Frontiers in microbiology. 2019;10:2182.

5. Devanga Ragupathi N, Muthuirulandi Sethuvel D, Triplicane Dwarakanathan H, Murugan D, Umashankar Y, Monk P, Karunakaran E, Veeraraghavan B. K. pneumoniaeThe Influence of Biofilms on Carbapenem Susceptibility and Patient Outcome in Device Associated Infections: Insights Into Phenotype vs Genome-Wide Analysis and Correlation. Frontiers in microbiology. 2020;11:591679.

6. Jung H, Sorbara M, Pamer E. TAM mediates adaptation of carbapenem-resistant Klebsiella pneumoniae to antimicrobial stress during host colonization and infection. PLoS pathogens. 2021;17(2):e1009309.

7. Zhang C, Hu D, Xu J, Ma M, Xing H, Yao K, Ji J, Xu Z. Polyphenol-Assisted Exfoliation of Transition Metal Dichalcogenides into Nanosheets as Photothermal Nanocarriers for Enhanced Antibiofilm Activity. ACS Nano. 2018;12(12):12347-56.

8. Karatan E, Watnick P. Signals, regulatory networks, and materials that build and break bacterial biofilms. Microbiology molecular biology reviews: MMBR. 2009;73(2):310-47.

9. Vuotto C, Longo F, Pascolini C, Donelli G, Balice M, Libori M, Tiracchia V, Salvia A, Varaldo P. Biofilm formation and antibiotic resistance in Klebsiella pneumoniae urinary strains. J Appl Microbiol. 2017;123(4):1003-18.

10. Galdiero E, Lombardi L, Falanga A, Libralato G, Guida M, Carotenuto R. Biofilms: Novel Strategies Based on Antimicrobial Peptides. Pharmaceutics 2019, 11(7).

11. Donlan RM, Costerton JW. Biofilms: survival mechanisms of clinically relevant microorganisms. Clin Microbiol Rev. 2002;15(2):167-93.

12. Gilbert-Girard S, Savijoki K, Yli-Kauhaluoma J, Fallarero A. Screening of FDA-Approved Drugs Using a 384-Well Plate-Based Biofilm Platform: The Case of Fingolimod. Microorganisms 2020, 8(11).

13. Schulz L, Kim S, Hartsell A, Rose W. Antimicrobial stewardship during a time of rapid antimicrobial development: Potential impact on industry for future investment. Diagn Microbiol Infect Dis. 2019;95(3):114857.

14. Xie Y, Yang W, Tang F, Chen X, Ren L. Antibacterial activities of flavonoids: structure-activity relationship and mechanism. Curr Med Chem. 2015;22(1):132-49.

15. Bhattacharya S. Are we in the polyphenols era? Pharmacognosy research. 2011;3(2):147.

16. Imran M, Rauf A, Abu-Izneid T, Nadeem M, Shariati M, Khan I, Imran A, Orhan I, Rizwan M, Atif M, et al. Luteolin, a flavonoid, as an anticancer agent: A review. Biomedicine pharmacotherapy = Biomedecine pharmacotherapie. 2019;112:108612.

17. Yahfoufi N, Alsadi N, Jambi M, Matar C. The Immunomodulatory and Anti-Inflammatory Role of Polyphenols. Nutrients 2018, 10(11).

18. Colunga Biancatelli R, Berrill M, Catravas J, Marik P: Quercetin and Vitamin C: An Experimental, Synergistic Therapy for the Prevention and Treatment of SARS-CoV-2 Related Disease (COVID-19). Frontiers in immunology 2020, 11:1451.

19. Lopes L, Dos Santos Rodrigues J, Magnani M, de Souza E, de Siqueira-Júnior J. Inhibitory effects of flavonoids on biofilm formation by Staphylococcus aureus that overexpresses efflux protein genes. Microb Pathog. 2017;107:193-7.

20. Uckoo RM, Jayaprakasha GK, Vikram A, Patil BS. Polymethoxyflavones Isolated from the Peel of Miaray Mandarin (Citrus miaray) Have Biofilm Inhibitory Activity in Vibrio harveyi. J Agric Food Chem. 2015;63(32):7180-9.

21. Paczkowski J, Mukherjee S, McCready A, Cong J, Aquino C, Kim H, Henke B, Smith C, Bassler B. Pseudomonas aeruginosaFlavonoids Suppress Virulence through Allosteric Inhibition of Quorum-sensing Receptors. J Biol Chem. 2017;292(10):4064-76.

22. Qayyum S, Sharma D, Bisht D, Khan A. Identification of factors involved in Enterococcus faecalis biofilm under quercetin stress. Microb Pathog. 2019;126:205-11.

23. Raorane CJ, Lee JH, Kim YG, Rajasekharan SK, García-Contreras R, Lee J. Antibiofilm and Antivirulence Efficacies of Flavonoids and Curcumin Against Acinetobacter baumannii. Frontiers in microbiology. 2019;10:990.

24. Wang Z, Yu Q, Shen W, El Mohtar CA, Zhao X, Gmitter FG. Functional study of CHS gene family members in citrus revealed a novel CHS gene affecting the production of flavonoids. BMC Plant Biol. 2018;18(1):189.

25. Cutillas A, Carrasco A, Martinez-Gutierrez R, Tomas V, Tudela J. Thymus mastichina L. essential oils from Murcia (Spain): Composition and antioxidant, antienzymatic and antimicrobial bioactivities. PloS one. 2018;13(1):e0190790.

26. Kim S, Kim M, Cho S, Kim S, Kim J, Cho Y. Antioxidant activities and determination of phenolic compounds isolated from oriental plums (Soldam, Oishiwase and Formosa). Nutrition research practice. 2012;6(4):277-85.

27. Mandalari G, Bennett R, Bisignano G, Trombetta D, Saija A, Faulds C, Gasson M, Narbad A. Antimicrobial activity of flavonoids extracted from bergamot (Citrus bergamia Risso) peel, a byproduct of the essential oil industry. J Appl Microbiol. 2007;103(6):2056-64.

28. Sun Y, Li Y, Luo Q, Huang J, Chen J, Zhang R, Wang X. LuxS/Al-2 Quorum Sensing System in Edwardsiella piscicida Promotes Biofilm Formation and Pathogenicity. Infection and immunity 2020, 88(5).

29. Donelli G, Vuotto C, Cardines R, Mastrantonio P. Biofilm-growing intestinal anaerobic bacteria. FEMS Immunol Med Microbiol. 2012;65(2):318-25.

30. Wasfi R, Elkhatib W, Ashour H. Molecular typing and virulence analysis of multidrug resistant Klebsiella pneumoniae clinical isolates recovered from Egyptian hospitals. Scientific reports. 2016;6:38929.

31. Yang F, Deng B, Liao W, Wang P, Chen P, Wei J. High rate of multiresistant Klebsiella pneumoniae from human and animal origin. Infection drug resistance. 2019;12:2729-37.

32. Chen L, Wilksch J, Liu H, Zhang X, Torres V, Bi W, Mandela E, Cao J, Li J, Lithgow T, et al. Investigation of LuxS-mediated quorum sensing in Klebsiella pneumoniae. Journal of medical microbiology. 2020;69(3):402-13.

Page $7 / 15$ 
33. Wu M, Lin T, Hsieh P, Yang H, Wang J. Isolation of genes involved in biofilm formation of a Klebsiella pneumoniae strain causing pyogenic liver abscess. PloS one. 2011;6(8):e23500.

34. Pal S, Verma J, Mallick S, Rastogi S, Kumar A, Ghosh A. Absence of the glycosyltransferase WcaJ in Klebsiella pneumoniae ATCC13883 affects biofilm formation, increases polymyxin resistance and reduces murine macrophage activation. Microbiology. 2019;165(8):891-904.

35. Luo Y, Wang Y, Ye L, Yang J. Molecular epidemiology and virulence factors of pyogenic liver abscess causing Klebsiella pneumoniae in China. Clinical microbiology infection: the official publication of the European Society of Clinical Microbiology Infectious Diseases. 2014;20(11):0818-24.

36. Hasani A, Soltani E. Serotyping of Klebsiella pneumoniae and Its Relation with Capsule-Associated Virulence Genes, Antimicrobial Resistance Pattern, and Clinical Infections: A Descriptive Study in Medical Practice. Infection drug resistance. 2020;13:1971-80.

37. Nguyen G, Shaban L, Mack M, Swanson K, Bunnell S, Sykes D, Mecsas J. K. pneumoniaeSKAP2 is required for defense against infection and neutrophil respiratory burst. eLife 2020, 9.

38. Marcoleta A, Varas M, Ortiz-Severín J, Vásquez L, Berríos-Pastén C, Sabag A, Chávez F, Allende M, Santiviago C, Monasterio O, et al. Klebsiella pneumoniaeEvaluating Different Virulence Traits of Using and Zebrafish Larvae as Host Models. Front Cell Infect Microbiol. 2018;8:30.

39. León-Buitimea A, Garza-Cárdenas C, Garza-Cervantes J, Lerma-Escalera J, Morones-Ramírez J. The Demand for New Antibiotics: Antimicrobial Peptides, Nanoparticles, and Combinatorial Therapies as Future Strategies in Antibacterial Agent Design. Frontiers in microbiology. 2020;11:1669.

40. Biharee A, Sharma A, Kumar A, Jaitak V. Antimicrobial flavonoids as a potential substitute for overcoming antimicrobial resistance. Fitoterapia. 2020;146:104720.

41. Farhadi F, Khameneh B, Iranshahi M. Antibacterial activity of flavonoids and their structure-activity relationship: An update review. Phytother Res. 2019;33(1):13-40.

42. Meng X, Li Y, Zhou T, Sun W, Shan X, Gao X, Wang L. OFunctional Differentiation of Duplicated Flavonoid 3-Glycosyltransferases in the Flavonol and Anthocyanin Biosynthesis of. Frontiers in plant science. 2019;10:1330.

43. Lesjak M, Srai KS. S: Role of Dietary Flavonoids in Iron Homeostasis. Pharmaceuticals (Basel, Switzerland) 2019, 12(3).

44. Silva T, Cavalcanti Filho J, Barreto Fonsêca M, Santos N, Barbosa da Silva A, Zagmignan A, Abreu A, Sant'Anna da Silva A, Lima V, Silva N, et al: Buchenavia tetraphyllaProducts Derived from Leaves Have In Vitro Antioxidant Activity and Protect Larvae against-Induced Injury. Pharmaceuticals (Basel, Switzerland) 2020, 13(3).

45. Takó M, Kerekes E, Zambrano C, Kotogán A, Papp T, Krisch J, Vágvölgyi C. Plant Phenolics and Phenolic-Enriched Extracts as Antimicrobial Agents against Food-Contaminating Microorganisms. Antioxidants (Basel, Switzerland) 2020, 9(2).

46. Shivaprasad D, Taneja N, Lakra A, Sachdev D. In vitro and in situ abrogation of biofilm formation in E. coli by vitamin C through ROS generation, disruption of quorum sensing and exopolysaccharide production. Food Chem. 2021;341:128171.

47. Won M, Oyama L, Courtney S, Creevey C, Huws S. Can rumen bacteria communicate to each other? Microbiome. 2020;8(1):23.

48. Balestrino D, Haagensen J, Rich C, Forestier C. Characterization of type 2 quorum sensing in Klebsiella pneumoniae and relationship with biofilm formation. J Bacteriol. 2005;187(8):2870-80.

\section{Tables}

Table 1 RT-qPCR primers used for studying expression profiles in response to rutin treatment in biofilm of Klebsiella pneumoniae isolates 


\begin{tabular}{|c|c|c|c|c|}
\hline Target gene & Function description & Primer sequence $\left(5^{\prime} \rightarrow 3^{\prime}\right)$ & Product length(bp) & Source or reference \\
\hline \multirow[t]{2}{*}{$\mathrm{fimH}$} & \multirow[t]{2}{*}{ type I fimbriae biosynthesis } & CCATCACCGCAGGATCGTTA & \multirow[t]{2}{*}{109} & \multirow[t]{2}{*}{ This study } \\
\hline & & ACCACGTCGTTATTGGCGTA & & \\
\hline \multirow[t]{2}{*}{$m r k A$} & \multirow[t]{2}{*}{ type III fimbriae biosynthesis } & ACGTCTCTAACTGCCAGGC & \multirow[t]{2}{*}{115} & \multirow[t]{2}{*}{ [9] } \\
\hline & & TAGCCCTGTTGTTTGCTGGT & & \\
\hline \multirow[t]{2}{*}{$m r k D$} & \multirow[t]{2}{*}{ type III fimbriae biosynthesis } & ССАССААСТАТTСССТСGАA & \multirow[t]{2}{*}{226} & \multirow[t]{2}{*}{ [30] } \\
\hline & & ATGGAACCCACATCGACATT & & \\
\hline \multirow[t]{2}{*}{$w z m$} & \multirow[t]{2}{*}{ lipopolysaccharide (LPS) biosynthesis } & TGCCAGTTCGGCCACTAAC & \multirow[t]{2}{*}{148} & \multirow[t]{2}{*}{ [9] } \\
\hline & & GACAACAATAACCGGGATGG & & \\
\hline \multirow[t]{2}{*}{$w b b M$} & \multirow[t]{2}{*}{ lipopolysaccharide (LPS) biosynthesis } & ATGCGGGTGAGAACAAACCA & \multirow[t]{2}{*}{122} & \multirow[t]{2}{*}{ [9] } \\
\hline & & AGCCGCTAACGACATCTGAC & & \\
\hline \multirow[t]{2}{*}{$\operatorname{pgaA}$} & \multirow[t]{2}{*}{ poly- $\beta-1,6-\mathrm{N}$-acetyl-d-glucosamine polysaccharide secretion } & GCAGACGCTCTCCTATGTC & \multirow[t]{2}{*}{157} & \multirow[t]{2}{*}{ [9] } \\
\hline & & GCCGAGAGCAGGGGAATC & & \\
\hline \multirow[t]{2}{*}{ luxS } & \multirow[t]{2}{*}{ quorum-sensing } & AGTGATGCCGGAACGCGG & \multirow[t]{2}{*}{148} & \multirow[t]{2}{*}{ [9] } \\
\hline & & CGGTGTACCAATCAGGCTC & & \\
\hline \multirow[t]{2}{*}{ treC } & \multirow[t]{2}{*}{ capsular polysaccharide } & CCGACAGCGGGCAGTATT & \multirow[t]{2}{*}{71} & [38] \\
\hline & & CGCCGGATTCTCCCAGTT & & \\
\hline$w a b G$ & capsular polysaccharide & & & \\
\hline$r m p A$ & capsular polysaccharide & TTCAGGGAAATGGGGAGGGTA & 77 & This study \\
\hline & & AAACGTCAAGCCACATCCATTG & & \\
\hline $\operatorname{mag} A$ & capsular polysaccharide & GTCAGGCAGCTGTTGTGAAC & 119 & This study \\
\hline & & ACTTCTCGTATTTGCGGCGA & & \\
\hline wcaJ & colonic acid & AAATGGCGTACCGGTTGTTC & 163 & [35] \\
\hline & & CGGCCCTTTCGAGGTAGTTT & & \\
\hline alls & allantoin & GTTTTCCGCTAACGGTTCGG & 129 & This study \\
\hline & & ACCCAGCGCTACCCTTTTAC & & \\
\hline wcaG & capsule-associated virulence gene & TTCCACTACCCCAAACAACGA & 63 & [39] \\
\hline & & TGCGGCGCTTTCATGA & & \\
\hline entB & siderophore-associated gene & CTGCTGGGAAAAGCGATTGTC & 128 & This study \\
\hline & & ATGATCGACGGTTCGGCAAA & & \\
\hline 16S rRNA & reference gene & ATGACCAGCCACACTGGAAC & 157 & {$[40]$} \\
\hline & & СТTССTCCCCGCTGAAAGTA & & \\
\hline
\end{tabular}

Table 2 Ten components of flavonoids and their structure variations 


\begin{tabular}{|c|c|c|c|c|c|c|c|c|c|}
\hline \multirow[t]{2}{*}{ Code } & \multirow[t]{2}{*}{ Name } & \multicolumn{3}{|c|}{ Substituent } & \multirow[b]{2}{*}{ R4 } & \multirow[b]{2}{*}{ R5 } & \multirow[b]{2}{*}{ R6 } & \multicolumn{2}{|c|}{ Hydroxyl n (\%) } \\
\hline & & R1 & R2 & R3 & & & & R7 & \\
\hline \multicolumn{10}{|c|}{ Flavanone } \\
\hline 1 & Naringenin & $\mathrm{OH}$ & $\mathrm{H}$ & $\mathrm{OH}$ & $\mathrm{H}$ & $\mathrm{H}$ & $\mathrm{OH}$ & $\mathrm{H}$ & $3(42.86)$ \\
\hline 2 & Naringin & $\mathrm{OH}$ & $\mathrm{H}$ & O-Neo & $\mathrm{H}$ & $\mathrm{H}$ & $\mathrm{OH}$ & $\mathrm{H}$ & $2(28.57)$ \\
\hline 3 & Hesperidin & $\mathrm{OH}$ & $\mathrm{H}$ & O-Neo & $\mathrm{H}$ & $\mathrm{OH}$ & $\mathrm{OCH} 3$ & $\mathrm{H}$ & $2(28.57)$ \\
\hline \multicolumn{10}{|c|}{ Flavonols } \\
\hline 4 & Kaempferol & $\mathrm{OH}$ & $\mathrm{OH}$ & $\mathrm{H}$ & $\mathrm{OH}$ & $\mathrm{H}$ & $\mathrm{OH}$ & $\mathrm{H}$ & $4(57.14)$ \\
\hline 5 & Quercetin & $\mathrm{OH}$ & $\mathrm{OH}$ & $\mathrm{H}$ & $\mathrm{OH}$ & $\mathrm{OH}$ & $\mathrm{OH}$ & $\mathrm{H}$ & $5(71.43)$ \\
\hline 6 & Rutin & O-Rut & $\mathrm{OH}$ & $\mathrm{H}$ & $\mathrm{OH}$ & $\mathrm{OH}$ & $\mathrm{OH}$ & $\mathrm{H}$ & $4(57.14)$ \\
\hline \multicolumn{10}{|c|}{ Flavone } \\
\hline 7 & Apigenin & $\mathrm{H}$ & $\mathrm{OH}$ & $\mathrm{H}$ & $\mathrm{OH}$ & $\mathrm{H}$ & $\mathrm{H}$ & $\mathrm{OH}$ & $3(42.86)$ \\
\hline 8 & Luteolin & $\mathrm{H}$ & $\mathrm{OH}$ & $\mathrm{H}$ & $\mathrm{OH}$ & $\mathrm{H}$ & $\mathrm{OH}$ & $\mathrm{OH}$ & $4(57.14)$ \\
\hline \multicolumn{10}{|c|}{ Polymethoxylatedflavones } \\
\hline 9 & Sinensetin & $\mathrm{H}$ & $\mathrm{OCH} 3$ & $\mathrm{OCH} 3$ & $\mathrm{OCH} 3$ & $\mathrm{H}$ & $\mathrm{OCH} 3$ & $\mathrm{OCH} 3$ & $0(0)$ \\
\hline 10 & 3,5,6,7,8,3',4'-heptamethoxyflavone & $\mathrm{OCH} 3$ & $\mathrm{OCH} 3$ & $\mathrm{OCH} 3$ & $\mathrm{OCH} 3$ & $\mathrm{OCH} 3$ & $\mathrm{OCH} 3$ & $\mathrm{OCH} 3$ & $0(0)$ \\
\hline
\end{tabular}

Table 3 Characteristics of distribution and biofilm forming ability of 177 K. pneumoniae strains

\begin{tabular}{|c|c|c|c|c|c|c|}
\hline \multicolumn{3}{|l|}{ Distribution $\mathrm{n}(\%)$} & \multicolumn{4}{|c|}{ Biofilm model $n(\%)$} \\
\hline \multirow{2}{*}{\multicolumn{3}{|c|}{ Paediatric patients ( $\leq 16$ years) }} & None(-) & Weak(+) & Moderate(++) & Strong(+++) \\
\hline & & & $(n=21)$ & $(n=107)$ & $(n=30)$ & $(n=19)$ \\
\hline $0-28$ days & 15 & $8.47 \%$ & $5(2.82 \%)$ & $2(1.12 \%)$ & $2(1.13 \%)$ & $6(3.39 \%)$ \\
\hline 29 days -1 year & 5 & $2.82 \%$ & $1(0.56 \%)$ & $2(1.12 \%)$ & 0 & $2(1.12 \%)$ \\
\hline $2-16$ years & 7 & $3.95 \%$ & $2(1.12 \%)$ & $1(0.56 \%)$ & $4(2.26 \%)$ & 0 \\
\hline \multicolumn{7}{|c|}{ Adult patients ( $>16$ years) } \\
\hline $17-49$ years & 51 & $28.81 \%$ & $2(1.12 \%)$ & $25(14.12 \%)$ & $21(11.86 \%)$ & $3(1.69 \%)$ \\
\hline $50-65$ years & 47 & $26.55 \%$ & $1(0.56 \%)$ & $45(25.42 \%)$ & 0 & $1(0.56 \%)$ \\
\hline$>65$ year & 52 & $29.38 \%$ & $32(18.08 \%)$ & $11(6.21 \%)$ & $4(2.26 \%)$ & $5(2.82 \%)$ \\
\hline \multicolumn{7}{|l|}{ Gender } \\
\hline Male & 97 & $54.80 \%$ & $12(6.78 \%)$ & $64(36.16 \%)$ & $12(6.78 \%)$ & $9(5.08 \%)$ \\
\hline Female & 80 & $45.10 \%$ & $9(5.08 \%)$ & $43(24.29 \%)$ & $18(10.17 \%)$ & $10(5.65 \%)$ \\
\hline
\end{tabular}

Table 4 Minimum inhibitory concentration of 10 flavonoids against K. pneumoniae ATCC70060 and E.coli ATCC25922 


\begin{tabular}{|llll|}
\hline \multicolumn{2}{|c|}{ Flavonoids } & MIC $(\mu \mathrm{g} / \mathrm{mL})$ & \\
\hline Code & Name & K. pneumoniaeATCC700603 & E.coliATCC25922 \\
\hline 1 & Naringenin & $>1024$ & $>1024$ \\
\hline 2 & Naringin & $>1024$ & $>1024$ \\
\hline 3 & Hesperidin & $>1024$ & $>1024$ \\
4 & Kaempferol & $>1024$ & 1024 \\
\hline 5 & Quercetin & $>1024$ & $>1024$ \\
\hline 6 & Rutin & 1024 & 512 \\
\hline 7 & Apigenin & $>1024$ & $>1024$ \\
\hline 8 & Luteolin & $>1024$ & 1024 \\
\hline 9 & Sinensetin & $>1024$ & $>1024$ \\
\hline 10 & $3,5,6,7,8,3^{\prime}, 4^{\prime}$-heptamethoxyflavone & $>1024$ & $>1024$ \\
\hline
\end{tabular}

Table 5 Pearson's correlation coefficients between gene expression and biofilm biomass Note: ${ }^{*} \mathrm{P}<0.05$ vs control(-rutin); ${ }^{* *} \mathrm{P}<0.01$ vs control(-rutin).

\begin{tabular}{|c|c|c|c|c|c|c|c|c|c|c|c|c|c|c|}
\hline Coeffcient & mrkA & $m r k D$ & $w z m$ & $w b b M$ & $p g a A$ & IUxS & treC & wabG & $m p A$ & magA & wcaJ & alls & wcaG & entB \\
\hline fimH & $0.678^{*}$ & -0.216 & -0.327 & -0.414 & 0.005 & 0.007 & 0.034 & 0.104 & 0.362 & -0.331 & -0.341 & -0.079 & -0.081 & -0.297 \\
\hline$m r k A$ & & 0.036 & -0.553 & $-0.638^{*}$ & 0.331 & 0.281 & 0.353 & 0.392 & $0.578^{*}$ & -0.403 & -0.526 & -0.304 & 0.153 & -0.391 \\
\hline$m r k D$ & & & -0.053 & -0.232 & $0.921^{* k}$ & $0.941^{* *}$ & $0.898^{* *}$ & $0.872^{\text {*k }}$ & $0.748^{* *}$ & 0.465 & -0.135 & -0.177 & 0.032 & -0.059 \\
\hline wzm & & & & $0.955^{* \star}$ & -0.418 & -0.361 & -0.471 & -0.489 & -0.521 & $0.822^{* *}$ & $0.933^{* *}$ & $0.870^{\text {** }}$ & -0.073 & $0.708^{\text {th }}$ \\
\hline wbbM & & & & & $-0.584^{*}$ & -0.531 & $-0.631^{*}$ & $-0.650^{*}$ & $-0.695^{*}$ & $0.718^{\star *}$ & $0.969^{* *}$ & $0.867^{* *}$ & -0.006 & $0.801^{\text {th }}$ \\
\hline$p g a A$ & & & & & & $0.994^{* *}$ & $0.997^{* k}$ & $0.984^{* *}$ & $0.913^{* k}$ & 0.116 & -0.479 & -0.465 & 0.046 & -0.336 \\
\hline luxs & & . & & & & & $0.989^{* *}$ & $0.974^{* *}$ & $0.913^{\text {*k }}$ & 0.187 & -0.420 & -0.411 & 0.011 & -0.274 \\
\hline trec & & & & & & & & $0.988^{* *}$ & $0.920^{* *}$ & 0.057 & -0.528 & -0.509 & 0.035 & -0.380 \\
\hline wabG & & & & & & & & & $0.922^{* k}$ & 0.036 & -0.542 & -0.513 & 0.141 & -0.389 \\
\hline $\operatorname{rmpA}$ & & & & & & & & & & -0.020 & -0.561 & -0.460 & -0.061 & -0.400 \\
\hline $\operatorname{magA}$ & & & & & & & & & & & $0.790^{* *}$ & $0.720^{* *}$ & 0.010 & $0.731^{\text {t* }}$ \\
\hline wcaJ & & & & & & & & & & & & $0.914^{* *}$ & 0.021 & $0.888^{\text {t* }}$ \\
\hline alls & & & & & & & & & & & & & -0.112 & $0.797^{\text {th }}$ \\
\hline wcaG & & & & & & & & & & & & & & 0.172 \\
\hline entB & & & & & & & & & & & & & & \\
\hline
\end{tabular}

\section{Figures}




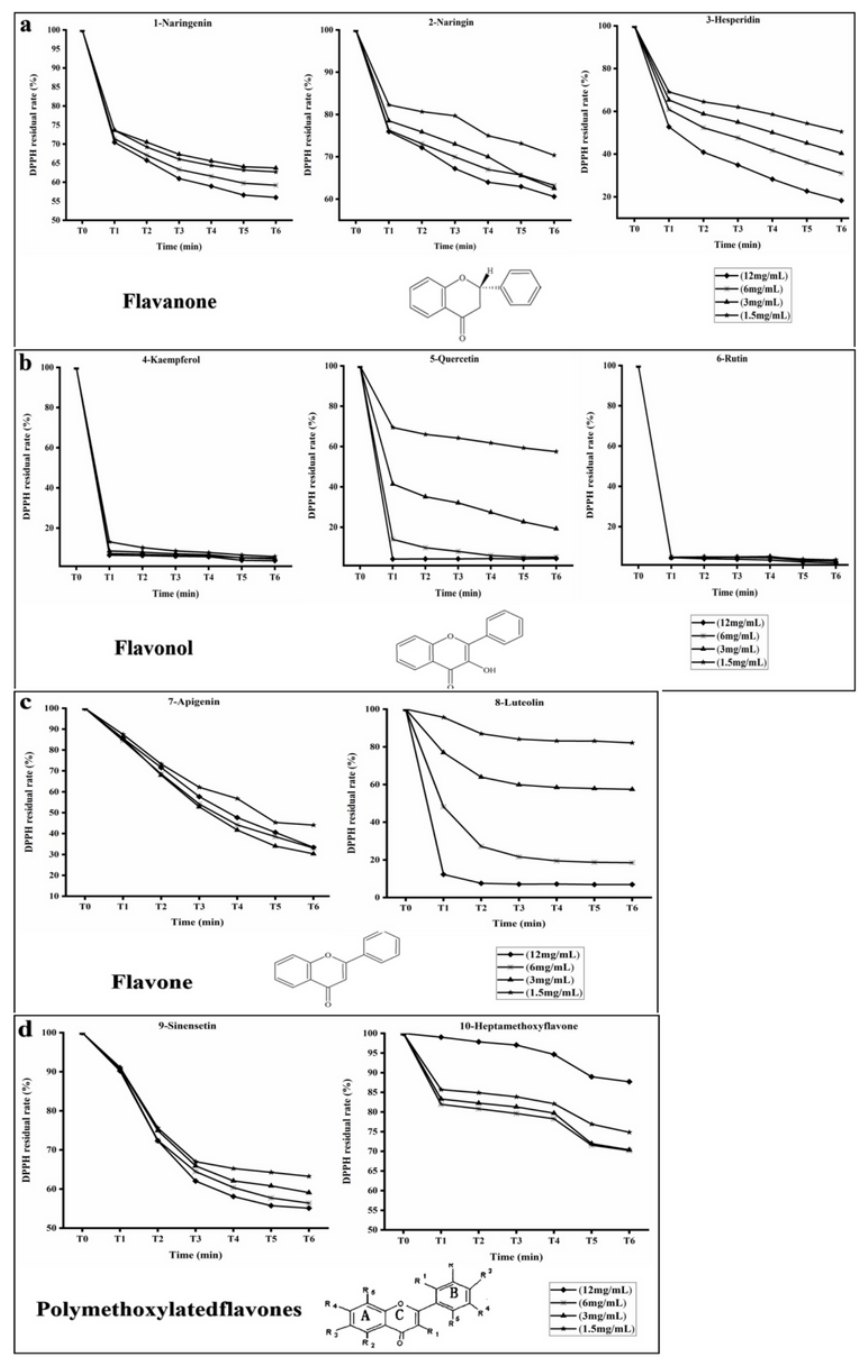

Figure 1

DPPH residual rate of 10 different flavonoids. Antioxidant ability of flavanones(a). Antioxidant ability of flavonols(b). Antioxidant ability of flavones(c). Antioxidant ability of polymethoxylatedflavones(d). 


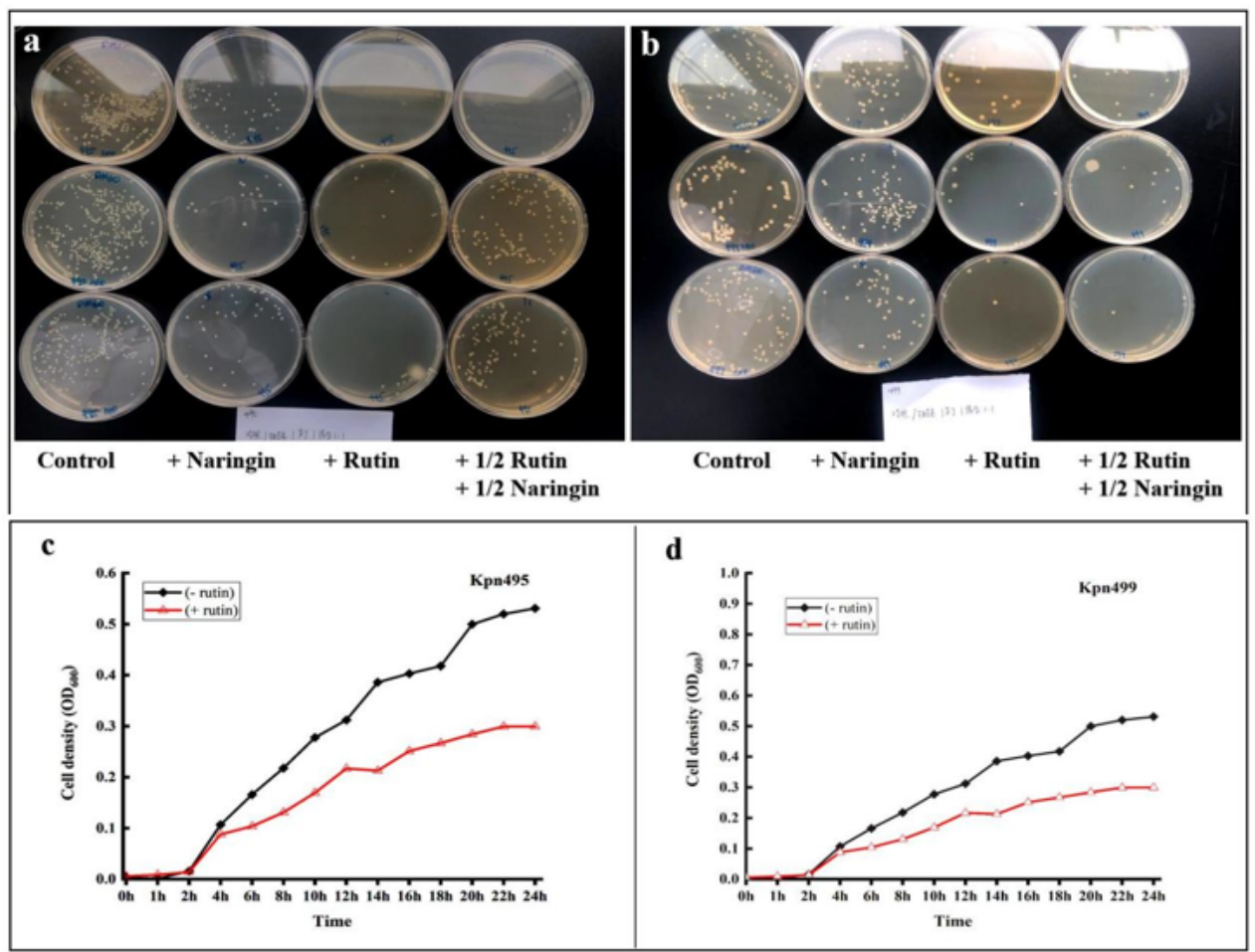

Figure 2

Inhibitory effect of flavonoids on the growth of drug-resistant K. pneumoniae. Effect of high concentration of naringin, rutin and the mixture( $1 / 2$ rutin $+1 / 2$ naringin) on Kpn495(a). Effect of high concentration of naringin, rutin and the mixture(1/2 rutin+1/2 naringin) on Kpn 499(b). Effect of rutin on the cell growth of K. pneumoniae isolates(c,d). 


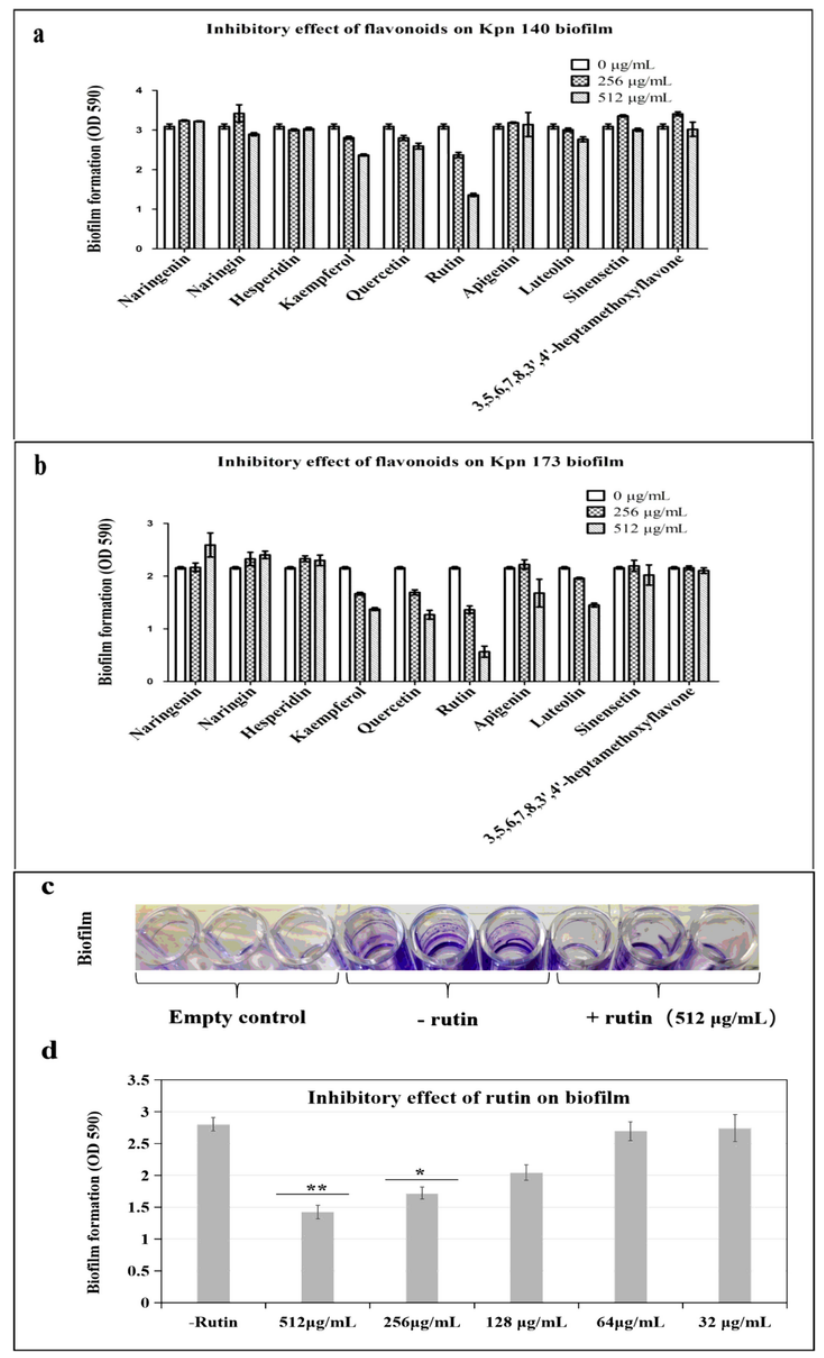

\section{Figure 3}

Inhibitory effect of flavonoids on the biofilm formation of K. pneumoniae. None dose-dependent effects of different flavonoids on biofilm formation by Kpn140(biofilm+++) (a). None dose-dependent effects of different flavonoids on biofilm formation by Kpn173(biofilm+++) (b). Effect of rutin on the biofilm formation of Kpn173(c). Effect of different concentrations of rutin on the biofilm formation of Kpn173(d). Biofilm was measured through crystal violet staining method. ${ }^{*} \mathrm{P}<0.01$ vs control(-rutin). ${ }^{* *} \mathrm{P}<0.05$ vs control(-rutin). 


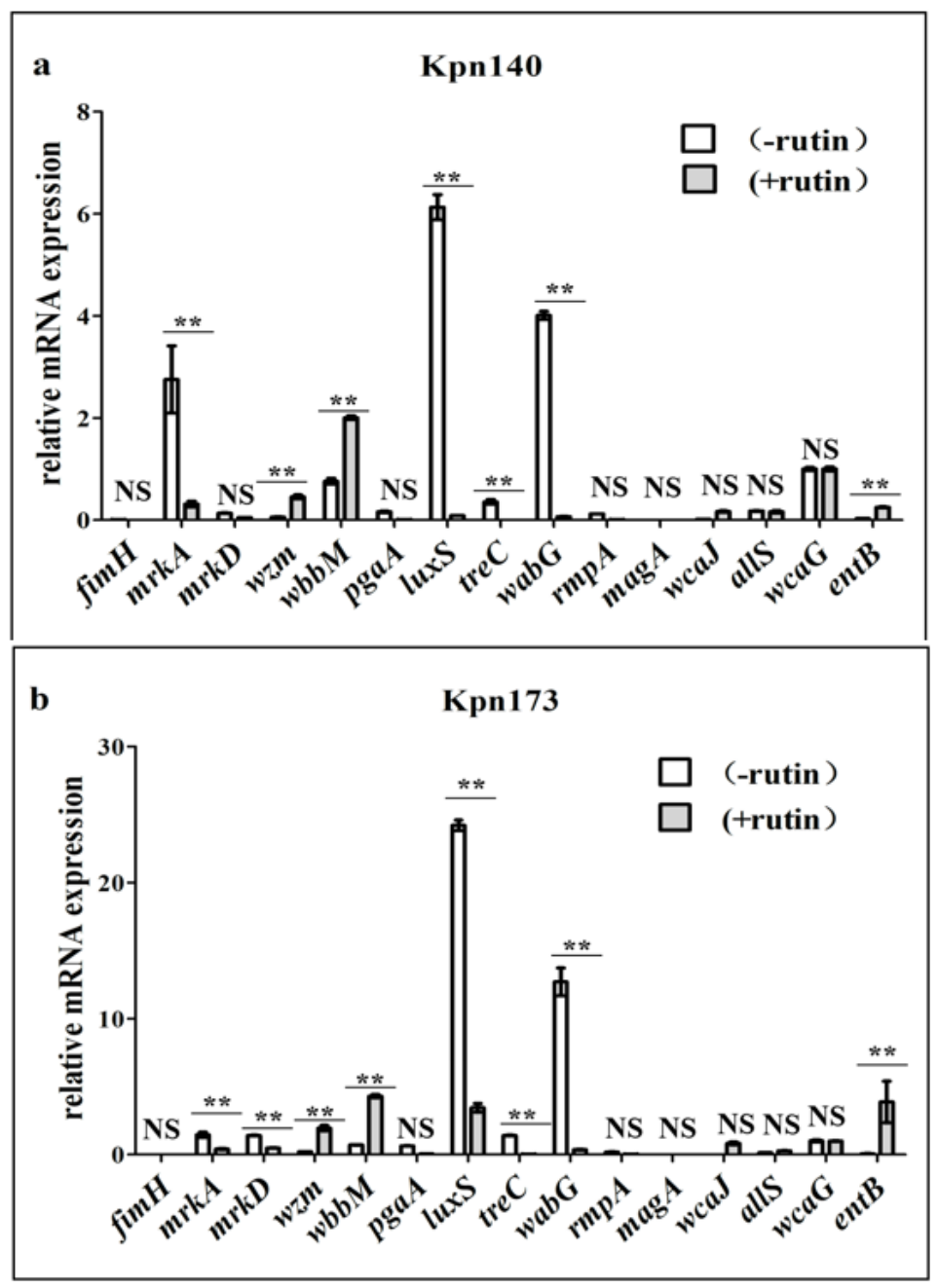

Figure 4

Gene expression profiles with and without rutin treatment. NS indicate not significant. ${ }^{*} \mathrm{P}<0.05$ vs control(-rutin); ${ }^{* *} \mathrm{P}<0.01$ vs control(-rutin).

\section{Supplementary Files}

This is a list of supplementary files associated with this preprint. Click to download.

- Detailinformationofthe177Kpstrains.xIsx

- StandardcurveforDPPHassay.xIsx

- Supplementaryfigure.docx 